\title{
A preliminary study identifies early postoperative lung volume changes in patients with non-small cell lung cancer following video-assisted thoracic surgery using CT volumetry
}

\author{
XIAOJUN DU ${ }^{1 *}$, HAOJUN LI ${ }^{1,2^{*}}$, LANGBO LIU $^{1}$, MIN ZHANG $^{1}$, ZHONGBEN TANG $^{1}$, \\ JIAN ZHANG ${ }^{1}$, PENG LIN ${ }^{1}$, HONG XIE ${ }^{3}$ and CHENG CHEN ${ }^{4}$ \\ ${ }^{1}$ Department of Thoracic Surgery, The Affiliated Hospital of Guizhou Medical University, Guiyang, Guizhou 550004; \\ ${ }^{2}$ Department of Thoracic Surgery, Sichuan Cancer Hospital and Institute, Sichuan Cancer Center, School of \\ Medicine, University of Electronic Science and Technology of China, Chengdu, Sichuan 610041; ${ }^{3}$ Department of \\ Radiology, The Affiliated Hospital of Guizhou Medical University, Guiyang, Guizhou 550004; ${ }^{4}$ Department of \\ Thoracic Surgery, The Affiliated Hospital of Zunyi Medical University, Zunyi, Guizhou 563099, P.R. China
}

Received August 16,2020; Accepted March 17, 2021

DOI: $10.3892 / \mathrm{mco} .2021 .2286$

\begin{abstract}
The present study aimed to investigate the changes in early postoperative lung volume in patients with non-small cell lung cancer (NSCLC) following video-assisted thoracic surgery (VATS) and to analyze the effects of the clinical characteristics on the lung volume of the patients. Therefore, 38 patients with NSCLC, who planned to undergo VATS at the Department of Thoracic Surgery, The Affiliated Hospital of Guizhou Medical University in June 2019, were enrolled into the present study. The clinical and computed tomography (CT) scan data from the patients was prospectively collected within 1 week preoperatively, and at 1, 3 and 6 months following surgery, then subsequently analyzed. A total of 34 patients successfully completed follow-up and were included in the datasets. The results showed that the volume of the right lung was larger compared with that in the left one, at each observational time point. The whole, right and left lung held the same trendline of volume changes, which was sharply decreased during the first postoperative month, increased quickly over the next 3 months, and slowly increased from months 3 to 6 . There were 7 patients, whose whole lung volume was increased at 6 months following surgery compared with that preoperatively. In addition, significant differences were observed between males and females in the whole, right and left lung volume. However, the differences on the postoperative
\end{abstract}

Correspondence to: Professor Cheng Chen, Department of Thoracic Surgery, The Affiliated Hospital of Zunyi Medical University, 149 Dalian Road, Zunyi, Guizhou 563099, P.R. China E-mail: sfgihpl@sina.com

*Contributed equally

Key words: lung volume, computed tomography, volumetry, video-assisted thoracic surgery, non-small cell lung cancer net expansion volume of the whole lung were not significant among sex, age, body mass index (BMI), smoking status and surgical side subgroups. The early changes of the postoperative lung volume were not linear, since the lung volume was significantly reduced during the first postoperative month, quickly increased in the next 3 months, and slowly increased from months 3 to 6 . Sex, age, BMI, smoking status and surgical sides was not found to affect the postoperative volume and net expansion of the whole lung following VATS lobectomy.

\section{Introduction}

Lung cancer has the second highest incidence and highest mortality rates in both males and females worldwide (1). It is well-known that surgical resection plays an important role in the comprehensive treatment of lung cancer. The preoperative evaluation and postoperative prediction of pulmonary function $(\mathrm{PF})$ is essential for lung resection, as PF can predict the risk of perioperative complications, and long-term disability and mortality following major lung resection (2-4). Furthermore, the prediction of the postoperative PF has been associated with long-term survival following surgery compared with that in preoperative lung function (5). Several methods have been developed to predict the postoperative PF (6-8), such as perfusion scans and segment counting methods; however, it has been suggested that these methods are inaccurate (9-11). The postoperative PF could be theoretically determined by the residual parenchymal volume following lung resection, since the adult lung generally does not have the ability to regenerate new alveolar septal tissues (12). In addition, the compensatory expansion of the remaining lung is not simply a consequence of hyperexpansion of the pre-existing alveolar septal tissue, but is accompanied by compensatory growth of the residual lung in volume and weight (13). Based on this theory, volumetric computed tomography (CT) has been widely used in several studies to observe the perioperative changes in lung volume or for analyzing the correlation between lung volume and PF tests (PFTs) (14-19). Therefore, volumetric CT has been considered 
to be more reliable and accurate in predicting postoperative $\mathrm{PF}$ compared with that in the segment-counting method (18-20). However, previous studies have only analyzed the changes in lung volume at two time points, preoperatively and postoperatively. Therefore, the present study aimed to continuously analyze the changes in the early postoperative lung volume in patients with non-small cell lung cancer (NSCLC) following video-assisted thoracic surgery (VATS) using volumetric CT.

\section{Materials and methods}

Clinical data collection. A total of 34 patients (58.56 \pm 9.00 years) with NSCLC, who planned to undergo VATS lobectomy in June 2019, were enrolled in the present study. The study was approved by the Human Ethics Committee of The Affiliated Hospital of Guizhou Medical University (Guizhou, China; approval no. 2020-244). Written informed consent was provided by all the patients, for the use of their data in scientific research at the beginning of enrollment. The clinical and radiological data of the patients, including sex, age, body mass index (BMI), smoking status, surgical sides and chest CT scans were prospectively collected within 1 week preoperatively (T0), and at 1 (T1), 3 (T2) and 6 months (T3) following surgery.

CT scan. The CT images were acquired using a LightSpeed VCT 64-detector scanner (GE Healthcare), with subjects holding their breath at the end of inspiration without contrast. The following CT parameters were used: $64 \times 0.625 \mathrm{~mm}$ detector configuration, 0.969 pitch, $120 \mathrm{kVp}$ tube energy, $250 \mathrm{~mA}$ tube current and $0.4 \mathrm{sec}$ gantry rotation (or $100 \mathrm{mAs}$ ). The CT scan images were saved as DICOM format.

Surgical procedure. All surgical procedures were performed by the same team using uniportal VATS, as previously described (21).

Lung volume measurement. The CT scan data was loaded into the Chest Imaging Platform and analyzed using the 3D Slicer software (version 4.10.2; macOS; https://download.slicer. org/). The Interactive Lobe Segmentation module was used to segment the lung lobes, and the Label Statistics module under the Quantification menu was used to compute the left and right sides, and whole lung volume (Fig. S1).

Statistical analysis. All the data from the recorded measurements was manually entered into the different analyses by the same researcher. Descriptive statistics were used to describe the demographic characteristics. Age and BMI were categorized into two groups (low and high) according to their mean values. Continuous variables were presented as the mean \pm standard deviation, while categorical values were presented as numbers. Net compensatory expansion volume was calculated as the lung volume at the current observation time minus the prior volume. Mixed two-way ANOVA was utilized to compare the differences between subgroups, and $\chi^{2}$ or Fisher's exact test was used for categorical data. Greenhouse-Geisser was used to adjust the degrees of freedom for the average number of tests of significance if $\mathrm{P}<0.05$ from the Mauchly's Test of Sphericity. A two-tailed $\mathrm{P}<0.05$ was considered to indicate a statistically significant
Table I. Demographic characteristics of the patients in the study.

\begin{tabular}{|c|c|c|c|}
\hline \multirow[b]{2}{*}{ Variable } & \multicolumn{2}{|c|}{ Sex } & \multirow[b]{2}{*}{ P-value } \\
\hline & $\begin{array}{c}\text { Female } \\
(n=19)\end{array}$ & $\begin{array}{c}\text { Male } \\
(n=15)\end{array}$ & \\
\hline Age, years & & & $>0.9999^{\mathrm{a}}$ \\
\hline Low & 10 & 8 & \\
\hline High & 9 & 7 & \\
\hline BMI & & & $0.510^{\mathrm{a}}$ \\
\hline Low & 9 & 9 & \\
\hline High & 10 & 6 & \\
\hline Smoking status & & & $<0.001^{\mathrm{b}}$ \\
\hline No & 19 & 7 & \\
\hline Yes & 0 & 8 & \\
\hline Smoking in males & & & - \\
\hline No & - & 7 & \\
\hline Yes & - & 8 & \\
\hline Surgical side & & & $0.491^{\mathrm{a}}$ \\
\hline Left & 11 & 6 & \\
\hline Right & 8 & 9 & \\
\hline
\end{tabular}

${ }^{\mathrm{a}} \chi^{2}$ test. ${ }^{\mathrm{b}}$ Fisher's exact test. -, not applicable. BMI, body mass index.

difference. All statistical analyses were performed using the SPSS v22.0 software (SPSS Inc.).

\section{Results}

Demographic characteristics. A total of 38 patients with NSCLC underwent VATS in June 2019 at the Department of Thoracic Surgery, The Affiliated Hospital of Guizhou Medical University, (Guizhou, China). None of the patients were treated with pneumonectomy or complex lobectomy. All the procedures were successfully performed using VATS, without converting to thoracotomy. Among all the patients, two were lost to follow-up at 1 and 3 months following surgery, respectively, and two at 6 months. Finally, there were 34 patients at the end of follow-up and were included in the datasets. The demographic characteristics of the included patients are listed in Table I. A total of 19 male patients were included. Among all the patients, 17 underwent left lateral VATS, while the remaining 17 received right lateral VATS. When the patients were divided by sex, there was no significant difference for the clinicopatholoical variables, except for smoking status where all eight (23.529\%) smokers were males.

Changes on the whole, left and right lung volume over time. The volume of the whole, left and right lung at four observation time points are shown in Table II. The mean T0 volume of the whole, left and right lung was 4,101.884 $\pm 1,328.220$, $1,899.614 \pm 646.058$ and 2,202.270 \pm 691.434 , respectively. At $\mathrm{T} 1, \mathrm{~T} 2$ and T3 months following surgery the lung volume were $3,030.510 \pm 931.542,1,381.809 \pm 670.565$ and 1,648.701 \pm 676.186 ; $3,436.707 \pm 1,103.550,1,586.401 \pm 739.232$ and 


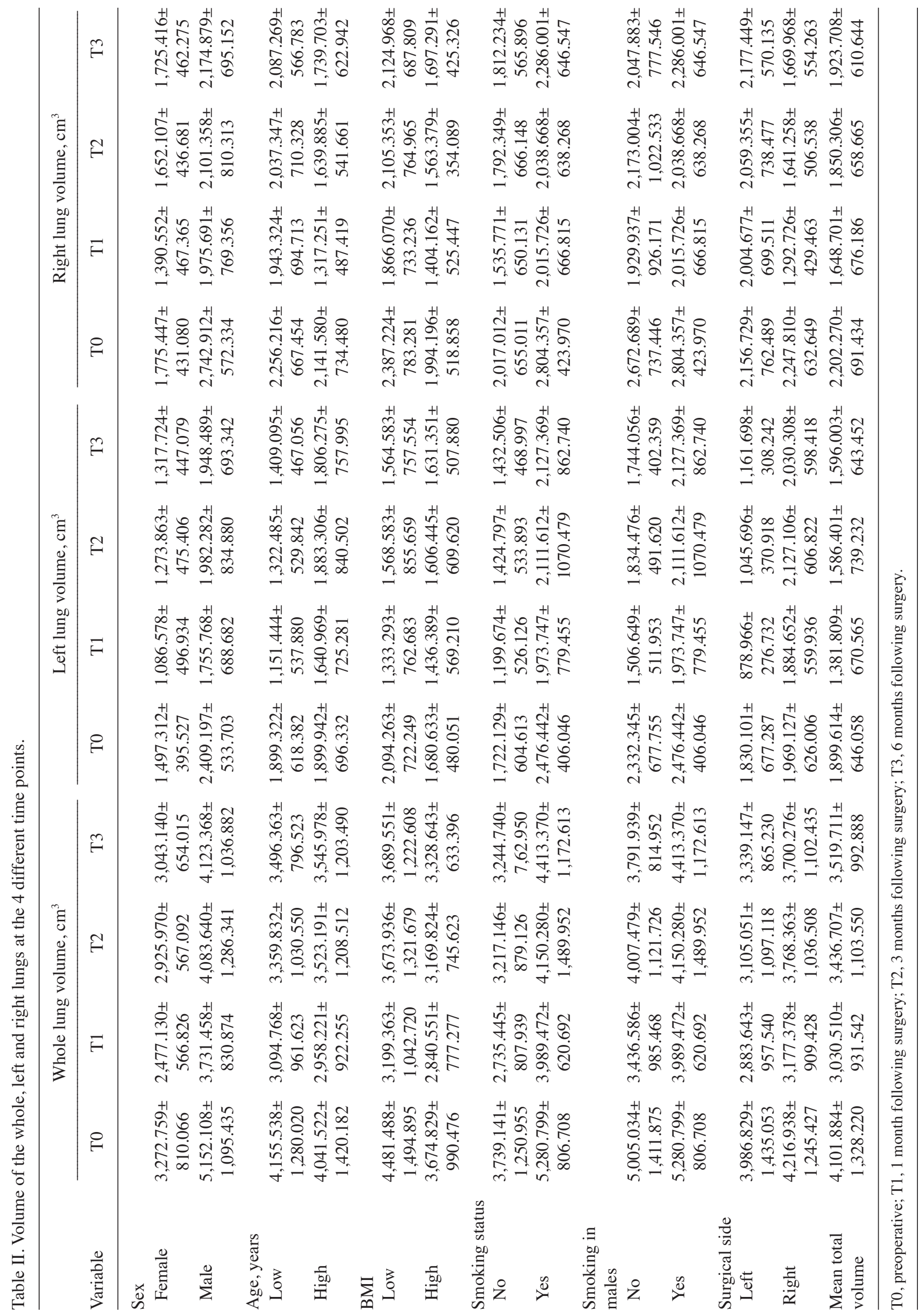




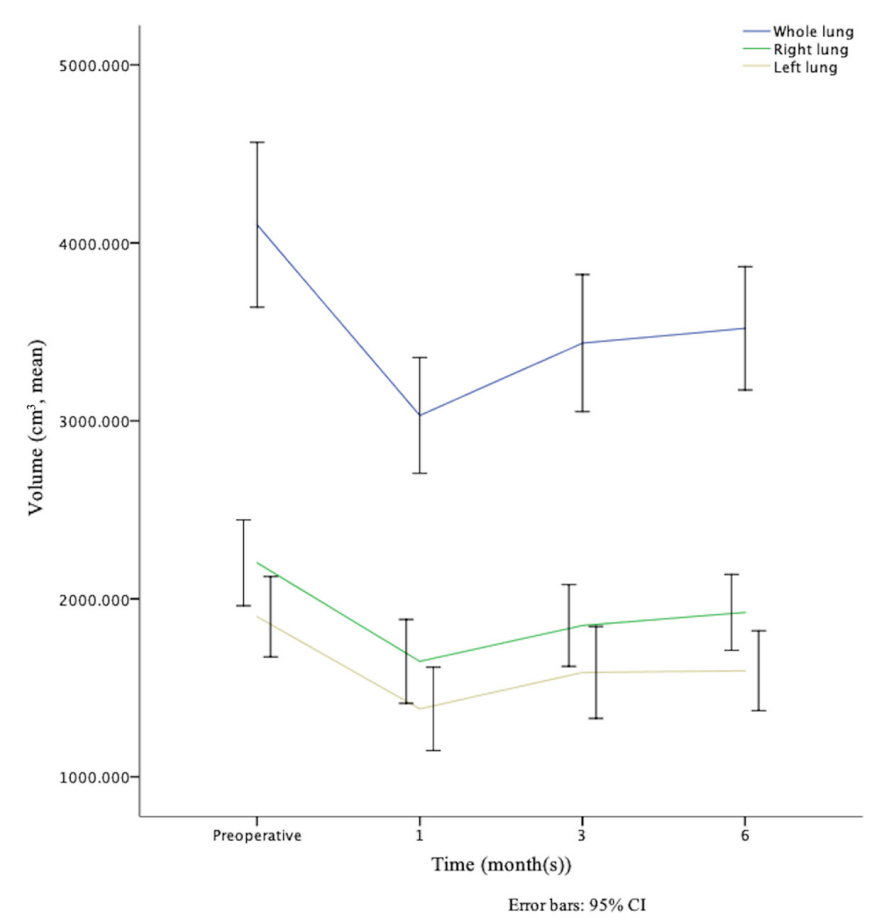

Figure 1. Changes in the whole, left and right lung volume at four different time points.

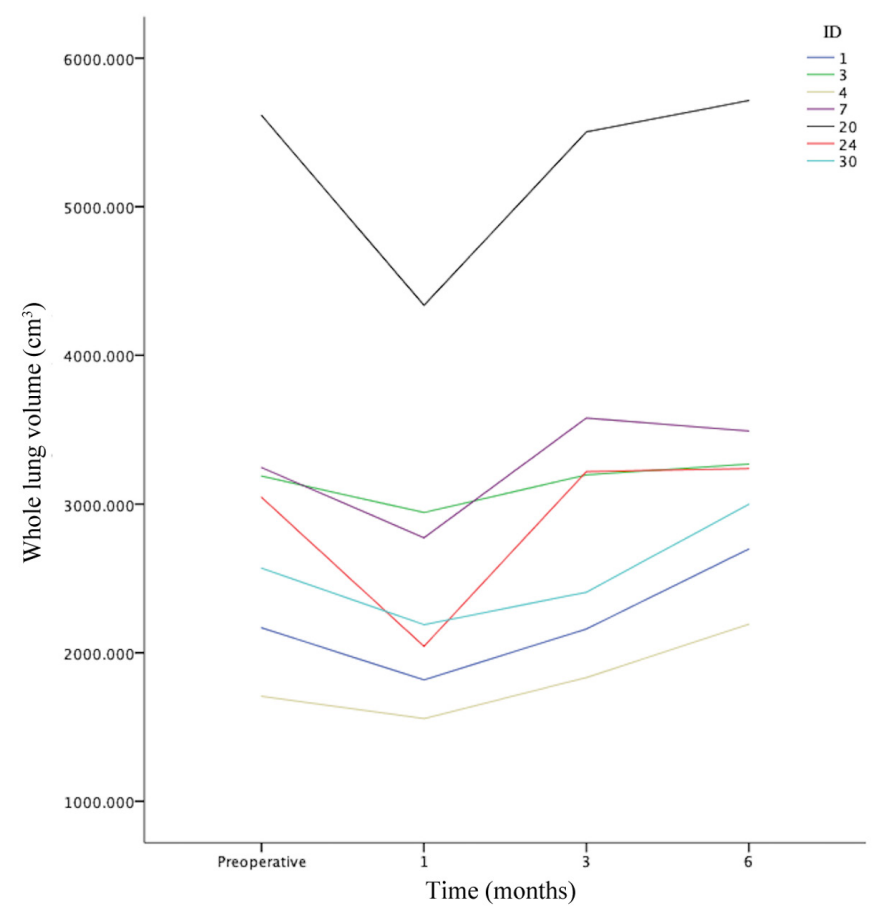

Figure 2. Lung volume changes in patients which had higher whole lung volume at 6 months following surgery compared with that preoperatively.

$1,850.306 \pm 658.665 ;$ and $3,519.711 \pm 992.889,1,596.003 \pm 643.452$ and $1,923.708 \pm 610.644$ for whole, left and right lung, respectively. The mean volume of the right lung was larger compared with that in the left one, at each time point. In addition, the trendline of volume changes in the whole, right and left lung were similar; it sharply decreased during the first postoperative month, quickly increased in the following 3 months, and slowly increased from the 3rd to the 6th month (Fig. 1). In a total of seven patients (20.588\%), the whole lung volume at 6 months following surgery was larger compared with that preoperatively (Fig. 2). However, the differences in the distribution of the observational variables were not significant (all $\mathrm{P}>0.05$ ) when the aforementioned seven patients were compared with those whose whole lung volume at 6 months following surgery was similar prior to surgery (Table III).

Changes in lung volume depends on surgical side. When the surgical sides were taken into consideration, the trendline of the ipsilateral lung volume was consistent with the aforementioned results. The postoperative changes on the left lung were consistent (Fig. 3A); however, the right lung rapidly recovered from $\mathrm{T} 1$ to $\mathrm{T} 2$, and then slightly recovered from $\mathrm{T} 2$ to $\mathrm{T} 3$ (Fig. 3B). With respect to the contralateral lung, the difference was notable. When the surgery was performed on the right side, the volume of the left lung was increased until T2, and then decreased slightly to just above the baseline (Fig. 3C). On the contrary, when the surgery was performed on the left side, the trendline of the right lung volume was as aforementioned, except that the mean volume at $\mathrm{T} 3$ increased to just above baseline (Fig. 3D).

\section{Results of mixed two-way ANOVA}

Whole, left and right lung volume. The results of the mixed two-way ANOVA are shown in Table IV. The differences in lung volume for each variable on the whole, left and right lung at the indicated observation time points (all $\mathrm{P}<0.05$ ) were significant compared with that for the main effect for the within-subject effects. This finding indicated that the volume of the whole, left and right lung was significantly changed over the course of time from T0 to T3. However, the differences were not all significant among diverse subgroups compared with the between-subject effects.

Sex. The differences on the whole, left and right lung volume were significant between the sex subgroups compared with the main effect for the between-subject effects (all $\mathrm{P}<0.05$ ). In addition, the whole, left and right lung volume in males was notably increased compared with females among the different observation time points (Table II; Fig. 4A-C). Furthermore, the interactive effects of time and sex on the whole and right lung volume was significant (both $\mathrm{P}<0.05$ ) (interaction with time under within-subject effects; Table IV), but not on that on the left lung volume, indicating that the changing trends on the whole and right lung volume were significantly different between males and females over time (from T0 to T3).

Age. The interactive effects of age and time were significantly different on the volume of the left and right lung (both $\mathrm{P}<0.05$ ) (interaction with time under within-subject effects); however, the differences on the whole, left and right lung volume were not significant between the age subgroups (all P>0.05) (main effect under between-subject effects) (Table IV). These findings indicated that the whole, left and right lung volume was similar between the low- and high-age groups at each observation time point, and that the changing trend of the whole lung volume, but not of that of the left and right lung, was the same between the age subgroups. 
Table III. Demographic characteristics of 7 patients in which whole lung volume was larger at 6 months postoperatively than preoperatively.

Whole lung volume larger postoperatively

Variable than preoperatively
Whole lung volume preoperatively than postoperatively
P-value

Sex

Female

Male

Age, years

Low

High

BMI

Low

High

Smoking status

No

Yes

Surgical side

Left

Right

6

1

3

4

2

5

6

1

3

4
0.104

13

14

15

12

16

11

20

7

14

13

BMI, body mass index.
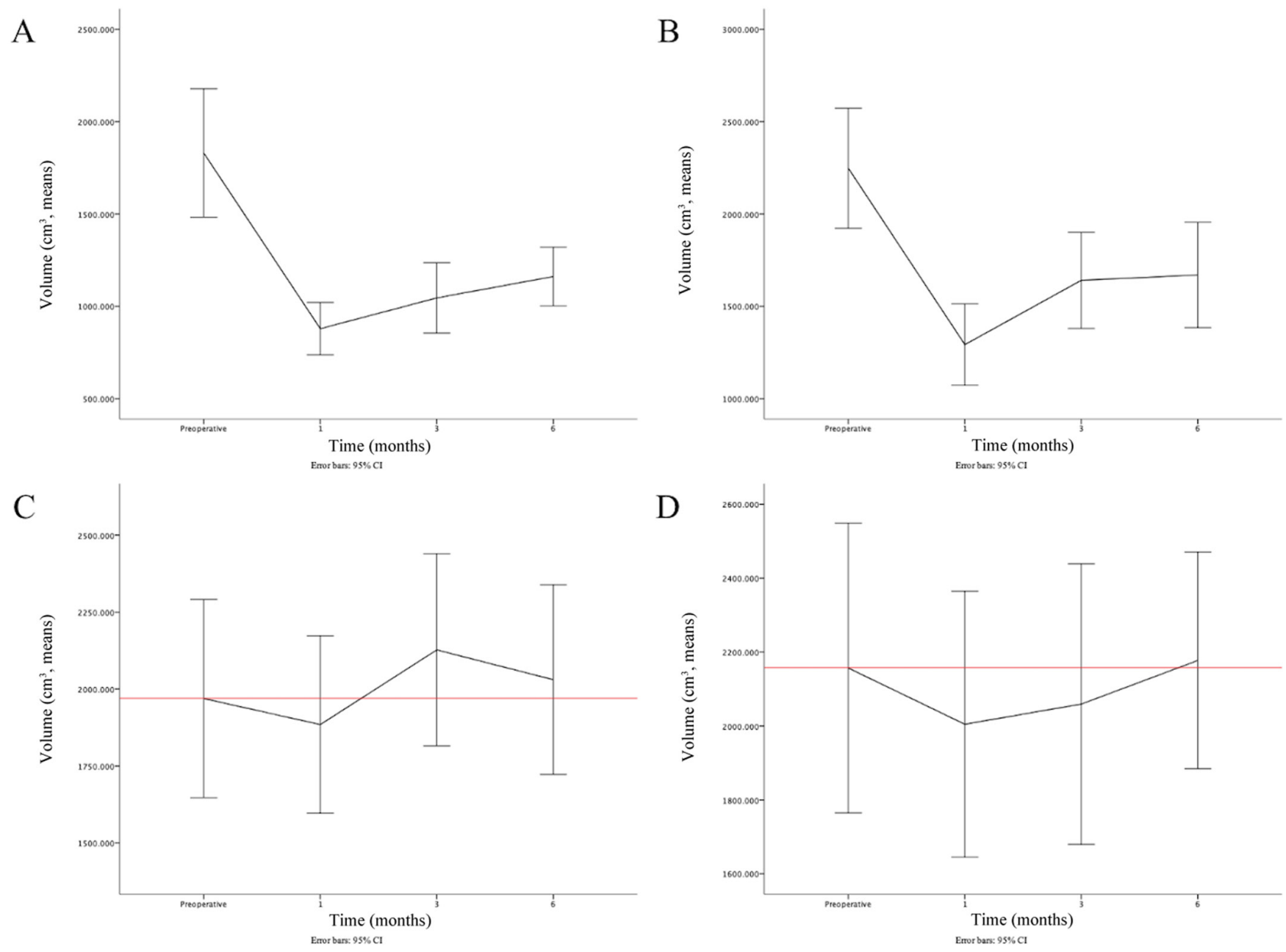

Figure 3. Trendline of the lung volume in association with the surgical side. The change of the (A) left and (B) right mean lung volume in ipsilateral lung surgery. The change of the (C) right and (D) left mean lung volume in contralateral lung surgery. The red line indicates the baseline. 
Table IV. Results of whole, right and left lung volume changes analyzed using mixed two-way ANOVA.

A, Whole lung volume

Within-subject effects

(at different time points)

\begin{tabular}{|c|c|c|c|c|c|c|c|c|}
\hline \multirow[b]{2}{*}{ Variable } & \multicolumn{2}{|c|}{ Main effect } & \multicolumn{2}{|c|}{ Interaction with time } & \multicolumn{2}{|c|}{ Intercept } & \multicolumn{2}{|c|}{ Main effect } \\
\hline & P-value & $\eta^{2}$ & P-value & $\eta^{2}$ & P-value & $\eta^{2}$ & $\mathrm{P}$-value & $\eta^{2}$ \\
\hline Sex & $<0.001$ & 0.541 & 0.001 & 0.157 & $<0.001$ & 0.957 & $<0.001$ & 0.437 \\
\hline Age & $<0.001$ & 0.488 & 0.503 & 0.024 & $<0.001$ & 0.924 & 0.979 & $<0.001$ \\
\hline BMI & $<0.001$ & 0.490 & 0.154 & 0.053 & $<0.001$ & 0.928 & 0.152 & 0.063 \\
\hline Smoking status & $<0.001$ & 0.460 & 0.144 & 0.054 & $<0.001$ & 0.934 & 0.002 & 0.265 \\
\hline Smoking in males & $<0.001$ & 0.580 & 0.614 & 0.045 & $<0.001$ & 0.956 & 0.444 & 0.046 \\
\hline Surgical side & $<0.001$ & 0.494 & 0.226 & 0.044 & $<0.001$ & 0.927 & 0.277 & 0.037 \\
\hline
\end{tabular}
effects (among diverse subgroups)
Between-subject

Within-subject effects

(at different time points)

\begin{tabular}{|c|c|c|c|c|c|c|c|c|}
\hline \multirow[b]{2}{*}{ Variable } & \multicolumn{2}{|c|}{ Main effect } & \multicolumn{2}{|c|}{ Interaction with time } & \multicolumn{2}{|c|}{ Intercept } & \multicolumn{2}{|c|}{ Main effect } \\
\hline & P-value & $\eta^{2}$ & P-value & $\eta^{2}$ & P-value & $\eta^{2}$ & P-value & $\eta^{2}$ \\
\hline Sex & $<0.001^{\mathrm{a}}$ & $0.339^{\mathrm{a}}$ & $0.269^{\mathrm{a}}$ & $0.040^{\mathrm{a}}$ & $<0.001$ & 0.919 & $<0.001$ & 0.345 \\
\hline Age & $<0.001^{\mathrm{a}}$ & $0.345^{\mathrm{a}}$ & $0.005^{\mathrm{a}}$ & $0.161^{\mathrm{a}}$ & $<0.001$ & 0.876 & 0.223 & 0.092 \\
\hline BMI & $<0.001^{\mathrm{a}}$ & $0.342^{\mathrm{a}}$ & $0.007^{\mathrm{a}}$ & $0.152^{\mathrm{a}}$ & $<0.001$ & 0.875 & 0.813 & 0.002 \\
\hline Smoking & $<0.001^{\mathrm{a}}$ & $0.254^{\mathrm{a}}$ & $0.860^{\mathrm{a}}$ & $0.003^{\mathrm{a}}$ & $<0.001$ & 0.895 & 0.002 & 0.257 \\
\hline Smoking in male & $0.005^{\mathrm{a}}$ & $0.364^{\mathrm{a}}$ & $0.597^{\mathrm{a}}$ & $0.034^{\mathrm{a}}$ & $<0.001$ & 0.926 & 0.331 & 0.073 \\
\hline Surgical sides & $<0.001^{\mathrm{a}}$ & $0.477^{\mathrm{d}}$ & $<0.001^{\mathrm{a}}$ & $0.484^{\mathrm{a}}$ & $<0.001$ & 0.922 & $<0.001$ & 0.403 \\
\hline
\end{tabular}

C, Right lung volume

Between-subject effects (among diverse subgroups)

Within-subject effects (at different time points)

\begin{tabular}{|c|c|c|c|c|c|c|c|c|}
\hline \multirow[b]{3}{*}{ Variable } & & \multirow{2}{*}{\multicolumn{2}{|c|}{ Main effect }} \\
\hline & \multicolumn{2}{|c|}{ Main effect } & \multicolumn{2}{|c|}{ Interaction with time } & \multicolumn{2}{|c|}{ Intercept } & & \\
\hline & P-value & $\eta^{2}$ & P-value & $\eta^{2}$ & $\mathrm{P}$-value & $\eta^{2}$ & P-value & $\eta^{2}$ \\
\hline Sex & $<0.001^{\mathrm{a}}$ & $0.397^{\mathrm{a}}$ & $0.004^{\mathrm{a}}$ & $0.147^{\mathrm{a}}$ & $<0.001$ & 0.936 & 0.002 & 0.267 \\
\hline Age & $<0.001$ & 0.380 & 0.011 & 0.109 & $<0.001$ & 0.920 & 0.070 & 0.099 \\
\hline BMI & $<0.001^{\mathrm{a}}$ & $0.346^{\mathrm{a}}$ & $0.762^{\mathrm{a}}$ & $0.010^{\mathrm{a}}$ & $<0.001$ & 0.924 & 0.024 & 0.149 \\
\hline Smoking & $<0.001^{\mathrm{a}}$ & $0.368^{\mathrm{a}}$ & $0.043^{\mathrm{a}}$ & $0.088^{\mathrm{a}}$ & $<0.001$ & 0.908 & 0.038 & 0.128 \\
\hline Smoking in male & $<0.001$ & 0.478 & 0.595 & 0.047 & $<0.001$ & 0.929 & 0.819 & 0.004 \\
\hline Surgical sides & $<0.001$ & 0.423 & $<0.001$ & 0.289 & $<0.001$ & 0.921 & 0.058 & 0.108 \\
\hline
\end{tabular}

${ }^{\mathrm{a}}$ Greenhouse-Geisser was used to adjust the degrees of freedom for the average number of tests of significance if $\mathrm{P}<0.05$ from the Mauchly's Test of Sphericity. BMI, Body mass index.

$B M I$. The differences on the right lung volume were significant between the BMI subgroups $(\mathrm{P}<0.05$; main effect under between-subject effects; Table IV). However, no significant differences were observed in the whole 

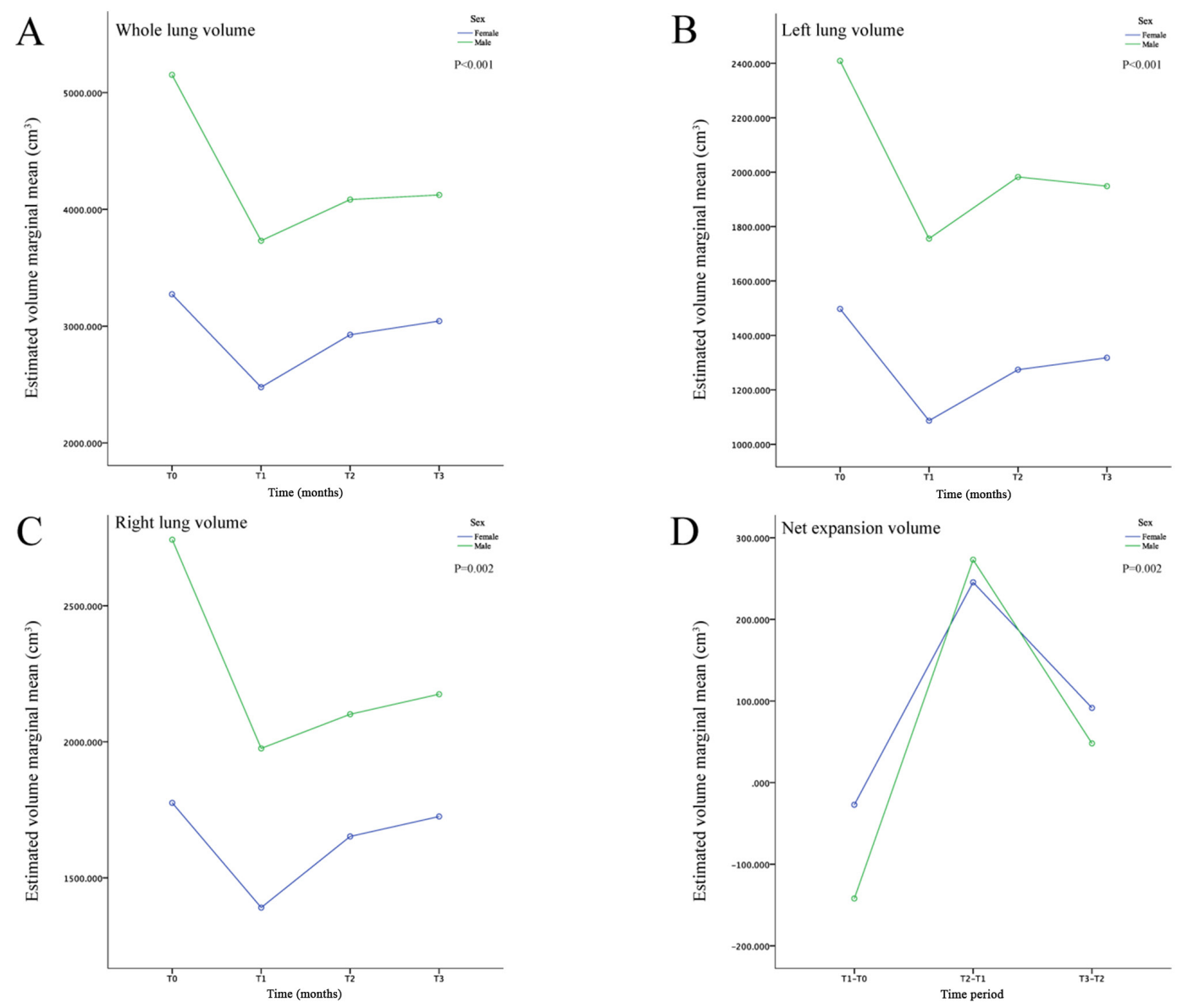

Figure 4. Profile plots of the estimated marginal mean for sex. The profile plots for the (A) whole, (B) left, and (C) right lung, and (D) net expansion.

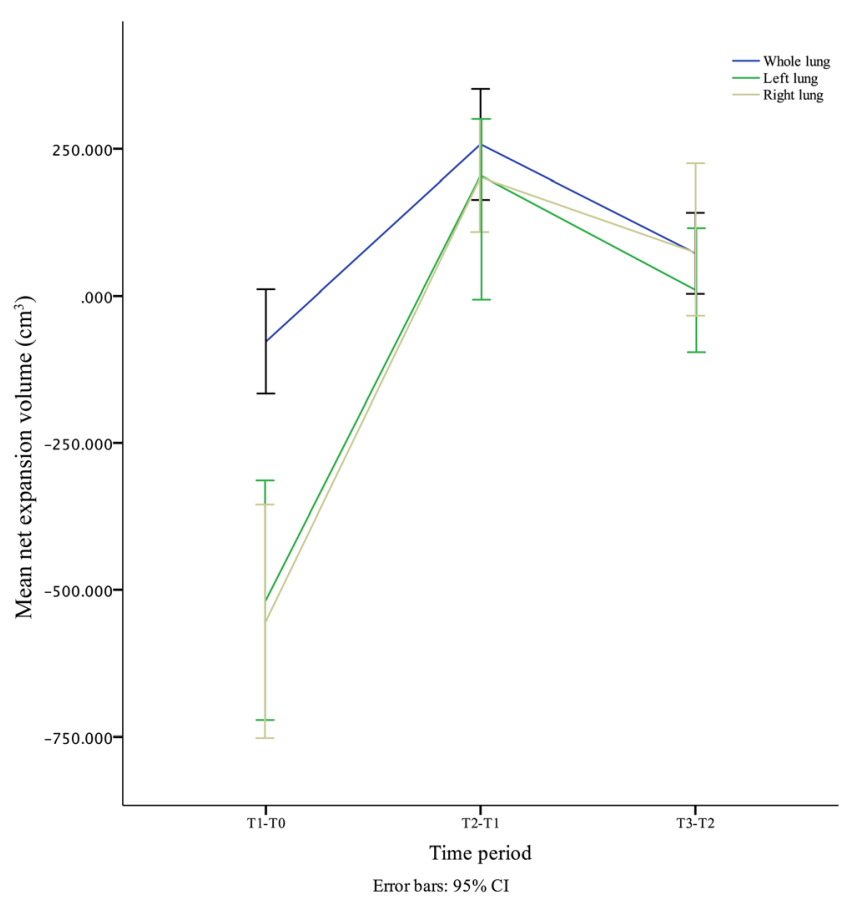

Figure 5. Net expansion changes in the whole, left and right lung volume at the indicated time points.

and left lung volume (both $\mathrm{P}>0.05$ ) (main effect under between-subject effects).
Smoking status. The differences on the whole, left and right lung volume were significant between smoking status and the between-subject effects (all $\mathrm{P}<0.05)$ (main effect under between-subject effects; Table IV); however, the differences were not significant when compared with the male subgroup (all $\mathrm{P}>0.05$ ) (main effect under between-subjects effects), since all smokers were males. This finding suggested that the whole, left and right lung volume was similar at each time point regardless of the smoking status.

Net expansion volume. The net expansion volume of the whole, left and right lung is presented in Table V. In general, the mean net expansion volume of the whole, left and right lung was sharply decreased during the first postoperative month, quickly increased in the next three months, and slowly decreased from the 3 rd to the 6 th month (Fig. 5). These changes were in accordance with the volume changes. The differences in age, BMI and surgical side in the left lung, as well as sex and surgical side in the right lung, were significant. However, these observational variables were not significant in the whole lung (Table VI). The combination of the aforementioned results indicated that the differences in the postoperative whole lung volume could be mainly attributed to the differences observed preoperatively regardless of the observational variables. For example, the lung volume in males was larger compared with that in females preoperatively and postoperatively, as the postoperative net expansion volume was similar between males and females (Fig. 4D). 


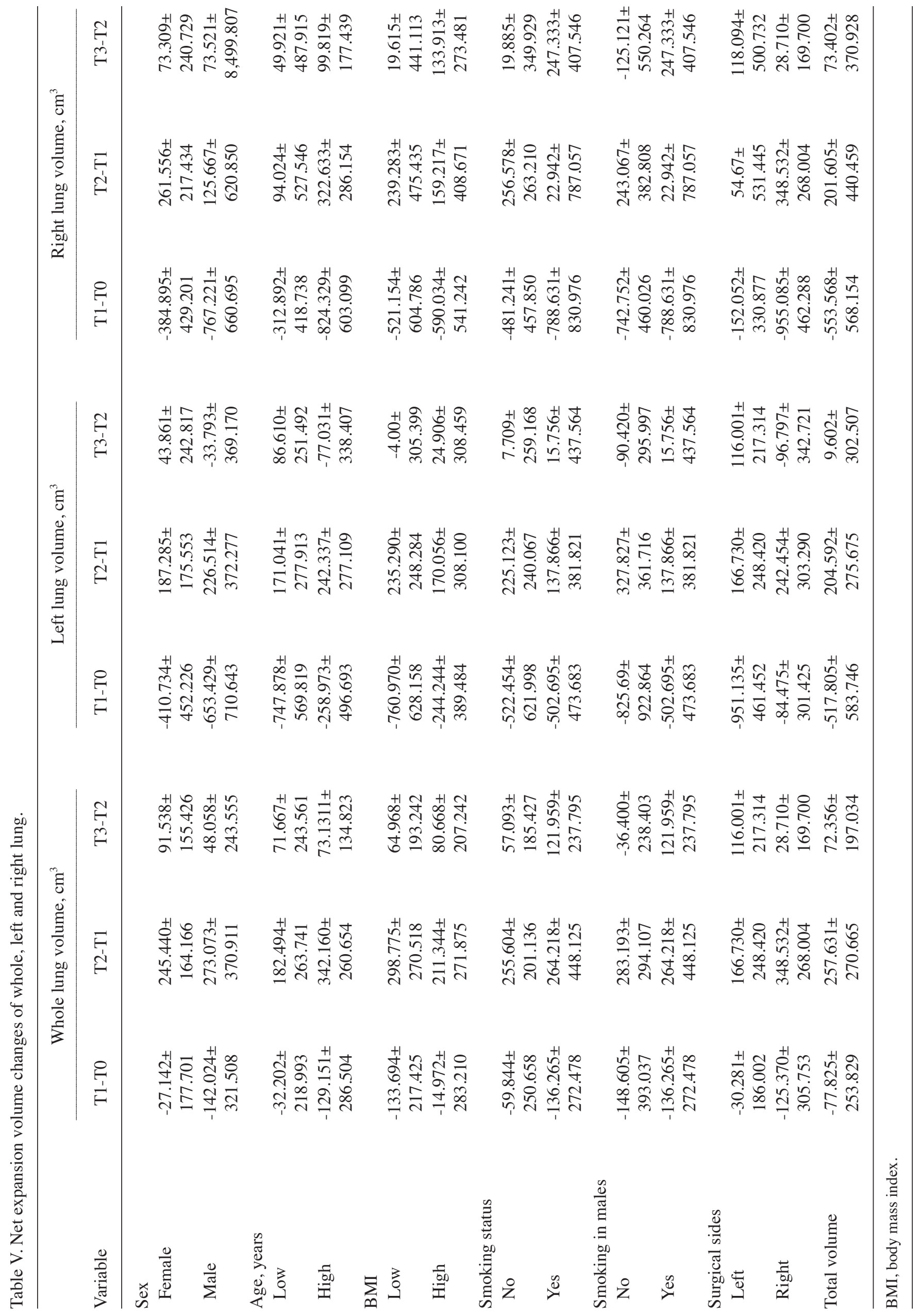


Table VI. Results of the net expansion volume changes in whole, right and left lung volume analyzed using mixed two-way ANOVA.

A, Whole lung volume

Within-subject effects

(at different time points)

\begin{tabular}{|c|c|c|c|c|c|c|c|c|}
\hline \multirow[b]{3}{*}{ Variable } & & \multirow{2}{*}{\multicolumn{2}{|c|}{ Main effect }} \\
\hline & \multicolumn{2}{|c|}{ Main effect } & \multicolumn{2}{|c|}{ Interaction with time } & \multicolumn{2}{|c|}{ Intercept } & & \\
\hline & $\mathrm{P}$-value & $\eta^{2}$ & P-value & $\eta^{2}$ & P-value & $\eta^{2}$ & $\mathrm{P}$-value & $\eta^{2}$ \\
\hline Sex & $<0.001^{\mathrm{a}}$ & $0.288^{\mathrm{a}}$ & $0.525^{\mathrm{a}}$ & $0.017^{\mathrm{a}}$ & $<0.001$ & 0.462 & 0.171 & 0.058 \\
\hline Age, years & $<0.001^{\mathrm{a}}$ & $0.298^{\mathrm{a}}$ & $0.166^{\mathrm{a}}$ & $0.057^{\mathrm{a}}$ & $<0.001$ & 0.472 & 0.504 & 0.014 \\
\hline BMI & $<0.001^{\mathrm{a}}$ & $0.277^{\mathrm{a}}$ & $0.300^{\mathrm{a}}$ & $0.036^{\mathrm{a}}$ & $<0.001$ & 0.469 & 0.625 & 0.008 \\
\hline Smoking status & $0.001^{\mathrm{a}}$ & $0.241^{\mathrm{a}}$ & $0.605^{\mathrm{a}}$ & $0.012^{\mathrm{a}}$ & $<0.001$ & 0.384 & 0.979 & $<0.001$ \\
\hline Smoking in males & $0.033^{\mathrm{a}}$ & $0.267^{\mathrm{a}}$ & $0.703^{\mathrm{a}}$ & $0.018^{\mathrm{a}}$ & 0.081 & 0.216 & 0.424 & 0.050 \\
\hline Surgical side & $<0.001^{\mathrm{a}}$ & $0.296^{\mathrm{a}}$ & $0.075^{\mathrm{a}}$ & $0.085^{\mathrm{a}}$ & $<0.001$ & 0.466 & 0.995 & $<0.001$ \\
\hline
\end{tabular}
effects (among diverse subgroups)
Between-subject

Within-subject effects

(at different time points)

Main effect

Variable

P-value $\eta^{2}$

Interaction with time

Sex

Age, years

BMI

Smoking status

Smoking in males

Surgical side

$\begin{array}{rl}<0.001 & 0.424 \\ <0.001 & 0.435 \\ <0.001 & 0.430 \\ <0.001 & 0.321 \\ 0.001 & 0.431 \\ <0.001 & 0.534\end{array}$

P-value $\quad \eta^{2}$

$\begin{array}{rr}0.449 & 0.025 \\ 0.009 & 0.136 \\ 0.016 & 0.121 \\ 0.906 & 0.003 \\ 0.472 & 0.056 \\ <0.001 & 0.390\end{array}$

C, Right lung volume
Between-subject effects (among diverse subgroups)

\section{Main effect}

$\frac{\text { Intercept }}{\text { P-value } \quad \eta^{2}}$

$\begin{array}{rr}0.001 & 0.280 \\ 0.002 & 0.262 \\ 0.001 & 0.274 \\ 0.007 & 0.209 \\ 0.020 & 0.351 \\ <0.001 & 0.387\end{array}$

P-value

$\eta^{2}$

\begin{tabular}{rr}
0.131 & 0.070 \\
0.029 & 0.140 \\
0.007 & 0.206 \\
0.789 & 0.002 \\
0.510 & 0.034 \\
$<0.001$ & 0.477 \\
\hline
\end{tabular}

Within-subject effects

(at different time points) effects (among diverse subgroups)

\begin{tabular}{|c|c|c|c|c|c|c|c|c|}
\hline \multirow[b]{3}{*}{ Variable } & \multicolumn{6}{|c|}{ (at different time points) } & \multirow{2}{*}{\multicolumn{2}{|c|}{$\frac{\text { diverse subgroups) }}{\text { Main effect }}$}} \\
\hline & \multicolumn{2}{|c|}{ Main effect } & \multicolumn{2}{|c|}{ Interaction with time } & \multicolumn{2}{|c|}{ Intercept } & & \\
\hline & P-value & $\eta^{2}$ & P-value & $\eta^{2}$ & P-value & $\eta^{2}$ & P-value & $\eta^{2}$ \\
\hline Sex & $<0.001^{\mathrm{a}}$ & $0.386^{\mathrm{a}}$ & $0.338^{\mathrm{a}}$ & $0.033^{\mathrm{a}}$ & $<0.001$ & 0.355 & 0.001 & 0.279 \\
\hline Age, years & $<0.001^{\mathrm{a}}$ & $0.417^{\mathrm{a}}$ & $0.015^{\mathrm{a}}$ & $0.134^{\mathrm{a}}$ & 0.002 & 0.266 & 0.174 & 0.057 \\
\hline BMI & $<0.001^{\mathrm{a}}$ & $0.373^{\mathrm{a}}$ & $0.669^{\mathrm{a}}$ & $0.011^{\mathrm{a}}$ & 0.003 & 0.248 & 0.842 & 0.001 \\
\hline Smoking status & $<0.001^{\mathrm{a}}$ & $0.352^{\mathrm{a}}$ & $0.176^{\mathrm{a}}$ & $0.054^{\mathrm{a}}$ & 0.001 & 0.300 & 0.118 & 0.075 \\
\hline Smoking in males & $0.009^{\mathrm{a}}$ & $0.361^{\mathrm{a}}$ & $0.465^{\mathrm{a}}$ & $0.050^{\mathrm{a}}$ & 0.001 & 0.593 & 0.692 & 0.012 \\
\hline Surgical side & $<0.001^{\mathrm{a}}$ & $0.449^{\mathrm{a}}$ & $<0.001^{\mathrm{a}}$ & $0.279^{\mathrm{a}}$ & $<0.001$ & 0.345 & $<0.001$ & 0.378 \\
\hline
\end{tabular}

Between-subject

${ }^{a}$ Greenhouse-Geisser was used to adjust the degrees of freedom for the average number of tests of significance if $\mathrm{P}<0.05$ from the Mauchly's test of sphericity. BMI, Body mass index.

Surgical side. The results showed that the changing trend of volume and net expansion volume was significant in the (all $\mathrm{P}<0.05)$ (main effect under the between-subjects effects; 
Table VII. Volume and net expansion volume changes of the ipsilateral and contralateral lung.

\begin{tabular}{|c|c|c|c|c|c|c|c|}
\hline \multirow[b]{2}{*}{ Surgical side } & \multicolumn{4}{|c|}{ Lung volume, $\mathrm{cm}^{3}$} & \multicolumn{3}{|c|}{ Net expansion volume, $\mathrm{cm}^{3}$} \\
\hline & T0 & $\mathrm{T} 1$ & $\mathrm{~T} 2$ & $\mathrm{~T} 3$ & T1-T0 & $\mathrm{T} 2-\mathrm{T} 1$ & T3-T2 \\
\hline Ipsilateral & $\begin{array}{c}2,038.956 \pm \\
679.271\end{array}$ & $\begin{array}{c}1,085.846 \pm \\
413.099\end{array}$ & $\begin{array}{c}1,343.477 \pm \\
531.478\end{array}$ & $\begin{array}{c}1,415.832 \pm \\
511.427\end{array}$ & $\begin{array}{c}-953.110 \pm \\
454.823\end{array}$ & $\begin{array}{c}257.631 \pm \\
270.665\end{array}$ & $\begin{array}{l}72.356 \pm \\
197.034\end{array}$ \\
\hline Contralateral & $\begin{array}{c}2,062.928 \pm \\
693.509\end{array}$ & $\begin{array}{c}1,944.664 \pm \\
626.872\end{array}$ & $\begin{array}{c}2,093.230 \pm \\
666.431\end{array}$ & $\begin{array}{c}2,103.879 \pm \\
580.349\end{array}$ & $\begin{array}{c}-118.264 \pm \\
313.543\end{array}$ & $\begin{array}{c}148.566 \pm \\
436.599\end{array}$ & $\begin{array}{l}10.649 \pm \\
436.361\end{array}$ \\
\hline
\end{tabular}

T0, preoperative; T1, 1 month after surgery; T2, 3 months after surgery; T3, 6 months after surgery.

Table VIII. Differences in volume and net expansion between ipsilateral and contralateral lungs according to surgical sides analyzed using mixed two-way ANOVA.

Within-subject effects

(at different time points)
Between-subject

effects (among

diverse subgroups)

\begin{tabular}{|c|c|c|c|c|c|c|c|c|}
\hline \multirow[b]{2}{*}{ Variable } & \multicolumn{2}{|c|}{ Main effect } & \multicolumn{2}{|c|}{ Interaction with time } & \multicolumn{2}{|c|}{ Intercept } & \multicolumn{2}{|c|}{ Main effect } \\
\hline & P-value & $\eta^{2}$ & P-value & $\eta^{2}$ & P-value & $\eta^{2}$ & P-value & $\eta^{2}$ \\
\hline Volume & $<0.001$ & 0.435 & $<0.001$ & 0.36 & $<0.001$ & 0.913 & $<0.001$ & 0.221 \\
\hline Net expansion & $<0.001^{\mathrm{a}}$ & $0.427^{\mathrm{a}}$ & $<0.001^{\mathrm{a}}$ & $0.295^{\mathrm{a}}$ & $<0.001$ & 0.364 & $<0.001$ & 0.427 \\
\hline
\end{tabular}

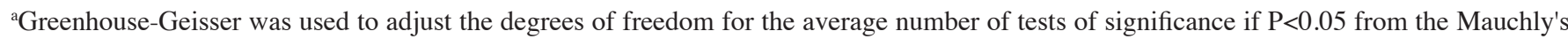
test of sphericity.

Tables VII and VIII). It indicated that the ipsilateral lung experienced more dramatic change of volume than contralateral after lobectomy.

\section{Discussion}

To the best of our knowledge, the present study reported for the first time the perioperative changes on lung volume. The main finding was that the whole, right and left lung exhibited a similar trendline of volume changes (Figs. 1-3). More specifically, the whole, right and left lung volumes were notably decreased during the first postoperative month (all $\mathrm{P}<0.05$ ), increased quickly in the next three months (all $\mathrm{P}<0.05)$ then increased more slowly from the 3rd to the 6th month (all $\mathrm{P}>0.05)$. In addition, the differences in all 3 lung volumes were all significant among the four observational time points (all $\mathrm{P}<0.05$ ) (Table II). The results indicated that the postoperative compensatory expansion of the bilateral lung, and consequently of the whole lung, occurred before the first month following surgery and lasted $\geq 6$ months postoperatively. Furthermore, the results showed that the postoperative lung volume did not change linearly. These findings are consistent with previous studies. For example, Nagamatsu et al (22) demonstrated that the forced expiratory volume in 1.0 second (FEV1) per square meter $\left(\mathrm{FEV} 1 / \mathrm{m}^{2}\right)$, a main parameter of $\mathrm{PF}$, was sharply decreased during the first postoperative month $(\mathrm{P}<0.001)$, then quickly increased for the next three months $(\mathrm{P}<0.001)$, and increased slowly for the next 3 months. Additional studies also revealed that FEV1 (23-25), vital capacity (VC) (24), forced vital capacity (FVC) (25) and diffusion capacity of the lung for carbon monoxide $\left(\mathrm{D}_{\mathrm{LCO}}\right)(23,24)$ were decreased in the early postoperative phase, after which they gradually improved, but not linearly. Further studies are required for identifying similar trendlines between the perioperative lung volume observed in the present study and PFTs used in previous studies; however, volumetric CT could be used to analyze perioperative PF or in combination with preoperative PFTs to predict the actual recovery of lung function following surgery. Furthermore, when the postoperative PF was predicted the predictive time points should also be also taken into consideration (22-25).

In addition, the results from the present study demonstrated that there were seven patients $(20.588 \%)$ with an increased whole lung volume 6th months following surgery compared with that preoperatively (Fig. 2). This could be attributed to preoperative obstructive pneumonia in central lung cancer or an enormous space occupying lesion in peripheral lung cancer. According to widely used algorithms, which were developed to predict postoperative PF based on the preoperative evaluated and resected segment, the postoperative PF should be inferior to the preoperative one (6-8). However, previous studies have already verified that it is imprecise to predict the postoperative function using these algorithms (9-11). This observation is reasonable and inevitable, since all of these algorithms are based on linear regression and ignore the variation of the postoperative lung volume re-expansion over time and the effects of compen- 
satory expansion on PF recovery. Furthermore, the PFTs require the effort of the patient, which sometimes vary with time and the patient (24). However, the results of the current study and previous studies confirmed that the postoperative lung volume or PF did not change linearly (22-25).

When the surgical side was taken into consideration, postoperative compensatory expansion was not only observed in the ipsilateral residual lung, but also in the contralateral intact lung (Fig. 3). Ueda et al (26) and Choe et al (17) used volumetric CT to observe the changes in the regional lung volume after lobectomy or segmentectomy. The authors revealed that not only did the ipsilateral residual lung lobe increase significantly, but also the contralateral lung. Ueda et al (26) suggested that the compensatory expansion of the bilateral residual lung following major resection, particularly after lobectomy, could contribute to improved postoperative residual pulmonary function, and that increased postoperative functional lung volume was significantly correlated with improved postoperative PF $(\mathrm{R}=0.6 ; \mathrm{P}<0.001)$.

Unlike previous studies (22-25), which investigated the changes in lung volume at only two different time points, the present study consistently recorded the perioperative changes. In addition, it was also found that the changing trends of the net compensatory expansion volume of the residual lung, which expanded rapidly between the 1st and 3rd postoperative month and then slowly for the next 3 months, were not linear in both the ipsilateral residual and contralateral intact lung (Fig. 5). This trend was similar with that observed in the whole lung, as aforementioned, and could be the root cause of the latter. With respect to the intactness of the contralateral lung, the only interpretation of the compensatory expansion could be the toward shift of the mediastinum ipsilateral chest, due to the ipsilateral chest volume loss attributed to lobectomy. The differences in the net compensatory expansion volume in the left and right lung were significant between the surgical sides $(\mathrm{P}<0.001$; Table VI), and the ipsilateral and contralateral lung $(\mathrm{P}<0.001$; Table VIII); however, no significant differences were observed in the whole lung $(\mathrm{P}=0.995$; Table VI; Fig. 5). This phenomenon could be attributed to the neutralization of the differences in the surgical side by summation when calculating the whole lung volume. Choe et al (17) also demonstrated that the differences on the postoperative whole lung volume were not significant between the surgical sides, although a significant difference on the compensatory expansion volume between the contralateral and ipsilateral lung was observed.

Furthermore, the current study showed that sex exerted a significant influence on postoperative early lung volume recovery. The trendline changes of the whole, left and right lung volume were similar between males and females; however, the perioperative mean lung volume in males was significantly larger compared with that in females $(\mathrm{P}<0.05$; Tables II and IV; Fig. 4). This finding could be due to the preoperative existing differences on lung volume. This was also in line with the study by Khieya (27) who reported that males were taller and more muscular with respect to body proportions, and not due to sex itself. This finding could also be verified by the absence of a significant difference in the net expansion volume of the whole and left lung between males and females (Table VI), and the fact that the adult lung does not generally have the ability to regenerate new alveolar septal tissues (12). Kim et al (28) showed that the differences on the preservation of FEV1 following VATS were not significant between male and female patients with NSCLC. In addition, Takahashi et al (29) confirmed that the sex was not associated with improvement of postoperative PF following lobectomy.

The results of the present study also demonstrated that age, BMI and smoking status had no effect on postoperative lung volume and net expansion of the whole lung following VATS lobectomy. Measuring lung volume alone cannot adequately describe lung function; however, variations on lung volume may reflect changes in its function. It is widely accepted that obesity, old age and smoking increases the risk of postoperative pulmonary complications (30); however, their effect on lung function remains controversial. Matsumoto et al (31) suggested that smoking did not affect the decreased volume of VC and FEV1 following pulmonary lobectomy. In addition, Kim et al (28) confirmed that the differences on FEV1 preservation following VATS were not significant between smokers and non-smokers, while Takahashi et al (29) showed that smoking was negatively correlated with improvement of postoperative PF following lobectomy.

Khieya (27) investigated 317 healthy individuals in the Southern Angami population, and found that BMI was not statistically associated with FEV1, FVC, peak expiratory flow and FEV1/FVC. Furthermore, Kobayashi et al (32) retrospectively reviewed the medical records of 445 patients who underwent surgery for lung cancer between 2001 and 2009, and verified that BMI had no effect on PF at years 1 and 5 year following lobectomy. Previous studies also confirmed that BMI had no effect on postoperative PFTs $(28,29)$.

Several studies have demonstrated that age was negatively correlated with PFTs $(5,27,28,33)$. However, a study showed that the differences on PFTs were not significant among the low, medium and high age groups (34). Takahashi et al (29) also found that age was not associated with improvement of postoperative PF following lobectomy. However, further studies are required to identify the effect of age, BMI and smoking on postoperative lung function following VATS lobectomy.

There are some limitations in the present preliminary study. Firstly, there was no investigation into the association between lung volume on CT scan and PFTs, since PFTs were not routinely performed following surgery. Secondly, due to the small number of patients, the changes in lung volume, with respect to the resected lobes were not analyzed. Therefore, these analyses will be performed in our future studies. Thirdly, the preoperative PFT was only performed in the patients. As this is a preliminary study, the aim was to investigate perioperative lung volume changes, and the PFT is currently being performed at all the follow-up time points in the ongoing study. Finally, a longer observation time is also required to reveal the lung volume changes one year or more following surgery.

Regardless of these limitations, the current study showed that the early changes on postoperative lung volume were not linear, since the lung volume was significantly decreased during the first postoperative month, rapidly increased in the next 3 months, then slowly increased from 3-6 months. In addition, the results demonstrated that sex, age, BMI, smoking status and surgical sides had no effect on the postoperative 
volume and net expansion of the whole lung following VATS lobectomy.

\section{Acknowledgements}

Not applicable.

\section{Funding}

This study was partly funded by the Wu Jieping Medical Foundation (grant no. 320.6750.18470).

\section{Availability of data and materials}

The datasets used and/or analyzed in the current study are available from the corresponding author on reasonable request.

\section{Authors' contributions}

$\mathrm{XD}$ and HL was involved in the conception and design of the study. CC provided administrative support. LL, MZ, ZT, JZ, PL and HX recruited the patients. LL, MZ, ZT, PL and HX collected and organized the data. XD and HL confirm the authenticity of all the raw data. All authors analyzed and interpreted the data, wrote the manuscript and provided final approval of the manuscript.

\section{Ethics approval and consent to participate}

This study was approved the Human Ethics Committee of The Affiliated Hospital of Guizhou Medical University (Guizhou, China; approval no. 2020-244). Medical record review was performed in accordance with the institutional ethics review board guidelines. Informed consent was provided by all individual participants included in the study.

\section{Patient consent for publication}

Patients signed informed consent regarding publishing their data and photographs.

\section{Competing interests}

The authors declare that they have no competing interests.

\section{References}

1. Siegel RL, Miller KD and Jemal A: Cancer statistics, 2019. CA Cancer J Clin 69: 7-34, 2019.

2. Selzer A and Sarkiss M: Preoperative pulmonary evaluation. Med Clin North Am 103: 585-599, 2019.

3. Lee H, Kim HK, Kang D, Kong S, Lee JK, Lee G, Shin S, Cho J, Zo JI, Shim YM and Park HY: Prognostic value of 6-Min walk test to predict postoperative cardiopulmonary complications in patients with non-small cell lung cancer. Chest 157: 1665-1673 2020.

4. Lakshminarasimhachar A and Smetana GW: Preoperative evaluation: Estimation of pulmonary risk. Anesthesiol Clin 34 71-88, 2016.

5. Ferguson MK, Watson S, Johnson E and Vigneswaran WT: Predicted postoperative lung function is associated with all-cause long-term mortality after major lung resection for cancer. Eur J Cardiothorac Surg 45: 660-664, 2014.
6. Juhl B and Frost N: A comparison between measured and calculated changes in the lung function after operation for pulmonary cancer. Acta Anaesthesiol Scand Suppl 57: 39-45, 1975.

7. Egeblad K, Aunsholt NA, Funder V and Nielsen PH: A simple method for predicting pulmonary function after lung resection. Scand J Thorac Cardiovasc Surg 20: 103-107, 1986.

8. Nakahara K, Monden Y, Ohno K, Miyoshi S, Maeda H and Kawashima Y: A method for predicting postoperative lung function and its relation to postoperative complications in patients with lung cancer. Ann Thorac Surg 39: 260-265, 1985.

9. Ontiveros N, Eapen-John D, Song J, Li L, Sheshadri A, Tian X, Ghosh N, Vaporciyan AA, Correa M, Walsh G, et al: Predicting postoperative lung function following lobectomy. Chest 152 : A640, 2017.

10. Varela G, Brunelli A, Rocco G, Marasco R, Jiménez MF, Sciarra V, Aranda JL and Gatani T: Predicted versus observed FEV1 in the immediate postoperative period after pulmonary lobectomy. Eur J Cardiothorac Surg 30: 644-648, 2006.

11. Brunelli A, Refai M, Salati M, Xiumé F and Sabbatini A: Predicted versus observed FEV1 and DLCO after major lung resection: A prospective evaluation at different postoperative periods. Ann Thorac Surg 83: 1134-1139, 2007.

12. Bremer JL: The fate of the remaining lung tissue after lobectomy or pneumonectomy. J Thorac Surg 6: 336-343, 1937.

13. Wakamatsu I, Matsuguma H, Nakahara R and Chida M: Factors associated with compensatory lung growth after pulmonary lobectomy for lung malignancy: An analysis of lung weight and lung volume changes based on computed tomography findings. Surg Today 50: 144-152, 2020.

14. Vinogradskiy Y, Jackson M, Schubert L, Jones B, Castillo R, Castillo E, Guerrero T, Mitchell J, Rusthoven C, Miften M and Kavanagh B: Assessing the use of 4DCT-ventilation in pre-operative surgical lung cancer evaluation. Med Phys 44: 200-208, 2017.

15. Suzuki H, Oishi H, Noda M, Watanabe T, Matsuda Y, Tominaga J, Sado T, Sakurada A, Kurosawa H, Takase K and Okada Y: Correlation between the native lung volume change and postoperative pulmonary function after single lung transplantation for lymphangioleiomyomatosis: Evaluation of lung volume by three-dimensional computed tomography volumetry. PLoS One 14: e0210975, 2019.

16. Gu S, Leader J, Zheng B, Chen Q, Sciurba F, Kminski N, Gur D and $\mathrm{Pu}$ J: Direct assessment of lung function in COPD using CT densitometric measures. Physiol Meas 35: 833-845, 2014.

17. Choe J, Lee SM, Chae EJ, Kim YH, Kim N and Seo JB: Evaluation of postoperative lung volume and perfusion changes by dual-energy computed tomography in patients with lung cancer. Eur J Radiol 90: 166-173, 2017.

18. Fourdrain A, De Dominicis F, Lafitte S, Iquille J, Prevot F, Lorne E, Monconduit J, Bagan P and Berna P: Quantitative computed tomography to predict postoperative FEV1 after lung cancer surgery. J Thorac Dis 9: 2413-2418, 2017.

19. Kobayashi K, Saeki Y, Kitazawa S, Kobayashi N, Kikuchi S, Goto Y, Sakai M and Sato Y: Three-dimensional computed tomographic volumetry precisely predicts the postoperative pulmonary function. Surg Today 47: 1303-1311, 2017.

20. Oswald NK, Halle-Smith J, Mehdi R, Nightingale P, Naidu B and Turner AM: Predicting postoperative lung function following lung cancer resection: A systematic review and meta-analysis. EClinicalMedicine 15: 7-13, 2019.

21. Sihoe ADL: The evolution of minimally invasive thoracic surgery: Implications for the practice of uniportal thoracoscopic surgery. J Thorac Dis 6 (Suppl 6): S604-S617, 2014.

22. Nagamatsu Y, Maeshiro K, Kimura NY, Nishi T, Shima I, Yamana $\mathrm{H}$ and Shirouzu K: Long-term recovery of exercise capacity and pulmonary function after lobectomy. J Thorac Cardiovasc Surg 134: 1273-1278, 2007.

23. Kim HK, Lee YJ, Han KN and Choi YH: Pulmonary function changes over 1 year after lobectomy in lung cancer. Respir Care 61: 376-382, 2016.

24. Yokoba M, Ichikawa T, Harada S, Naito M, Sato Y and Katagiri M: Postoperative pulmonary function changes according to the resected lobe: A 1-year follow-up study of lobectomized patients. J Thorac Dis 10: 6891-6902, 2018.

25. Kim SJ, Lee YJ, Park JS, Cho YJ, Cho S, Yoon HI, Kim K, Lee $\mathrm{JH}$, Jheon $\mathrm{S}$ and Lee CT: Changes in pulmonary function in lung cancer patients after video-assisted thoracic surgery. Ann Thorac Surg 99: 210-217, 2015. 
26. Ueda K, Tanaka T, Hayashi M, Li TS, Tanaka N and Hamano K: Computed tomography-defined functional lung volume after segmentectomy versus lobectomy. Eur J Cardiothorac Surg 37: $1433-1437,2010$

27. Khieya T: An Evaluation of the pulmonary function tests and their association with age and body mass index (BMI) in the southern angami population. J North East Indian Cult 3: 82-91, 2017.

28. Kim SJ, Ahn S, Lee YJ, Park JS, Cho YJ, Cho S, Yoon HI, Kim K, Lee JH, Jheon S and Lee CT: Factors associated with preserved pulmonary function in non-small-cell lung cancer patients after video-assisted thoracic surgery. Eur J Cardiothorac Surg 49: 1084-1090, 2016.

29. Takahashi Y, Matsutani N, Morita S, Dejima H, Nakayama T, Uehara $\mathrm{H}$ and Kawamura M: Predictors of long-term compensatory response of pulmonary function following major lung resection for non-small cell lung cancer: Long-term lung function after lobectomy. Respirology 22: 364-371, 2017.

30. Smetana GW: Preoperative pulmonary evaluation. N Engl J Med 340: 937-944, 1999.

31. Matsumoto R, Takamori S, Yokoyama S, Hashiguchi T, Murakami D, Yoshiyama K, Nishi T, Kashihara M, Mitsuoka M, Hayashida R, et al: Lung function in the late postoperative phase and influencing factors in patients undergoing pulmonary lobectomy. J Thorac Dis 10: 2916-2923, 2018.
32. Kobayashi N, Kobayashi K, Kikuchi S, Goto Y, Ichimura H, Endo K and Sato Y: Long-term pulmonary function after surgery for lung cancer. Interact Cardiovasc Thorac Surg 24: 727-732, 2017.

33. Behera A, Behera BK, Dash S and Mishra S: Variation of pulmonary function tests with relation to increasing age in healthy adults. Int J Health Sci Res 4: 136-141, 2014.

34. Britto RR, Zampa CC, Oliveira TA, de Oliveira TA, Prado LF and Parreira VF: Effects of the aging process on respiratory function. Gerontology 55: 505-510, 2009.

(7) (3) This work is licensed under a Creative Commons Attribution-NonCommercial-NoDerivatives 4.0 International (CC BY-NC-ND 4.0) License. 